International Journal of Social Sciences and Humanities
Available online at http://sciencescholar.us/journal/index.php/ijssh
Vol. 3 No. 3, December 2019, pages: $60 \sim 70$
e-ISSN: 2550-7001, p-ISSN: 2550-701X
https://doi.org/10.29332/ijssh.v3n3.361

\title{
Approaches to Evaluation Assumed by Teachers on Teaching Process - Learning
}

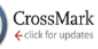

\begin{abstract}
Maria Antonia Velez Tuarez a, Mariela Alexandra Calderon Delgado bonald Ivan Zamora Delgado ${ }^{\text {c, }}$ Julio Eduardo Vallejo Romero ${ }^{\mathrm{d}}$
\end{abstract}

Article history: Received 09 April 2019, Accepted: 31 August 2019, Published: 15 November 2019

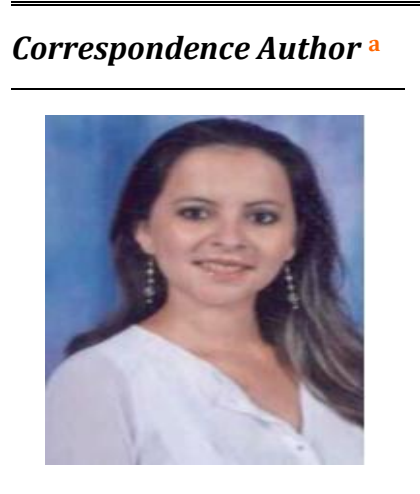

Keywords

authentic evaluation; evaluation approaches; learning evaluation; renewal evaluation practices; teaching - learning;

\begin{abstract}
Evaluation is a central issue in the educational process because it can define the success or failure of that process. The purpose of this article was to investigate the evaluation approaches that teachers assume in the teaching and learning process in the Educational Unit "Edwin Hernán Mendoza Bravo", of the Colón parish, to learn how the teacher performs the evaluation practices in their daily work The research that was carried out was of exploratory type and with a descriptive and systematic methodology supported in the review of bibliographic sources of the specialized literature. The technique and instrument that was used was the survey to achieve, interpret and reveal the results obtained, according to these, it was possible to reach the following conclusions: Many teachers do not usually apply the educational evaluation in their pedagogical work and focus on the tests or exams to obtain final results. Authentic evaluation and innovative strategies are unimportant elements because traditional techniques and instruments such as the written test and the questionnaire still prevail.
\end{abstract}

e-ISSN: 2550-7001, p-ISSN: 2550-701X ๑ Copyright 2019. The Author. SS Journals Published by Universidad Técnica de Manabí. This is an open-access article under the CC BY-SA 4.0 license (https://creativecommons.org/licenses/by-sa/4.0/) All rights reserved.

\section{Contents}

Abstract 60

1. Introduction 61

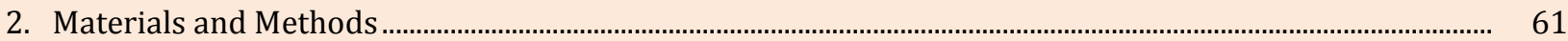

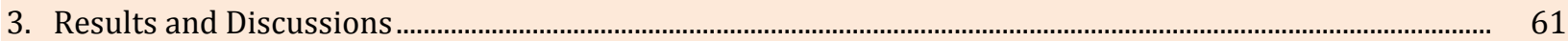

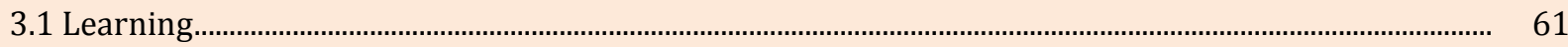

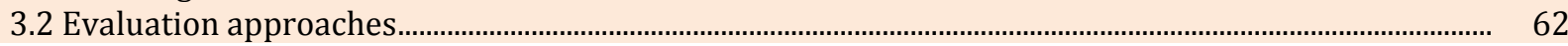

a Pontificia Universidad Católica del Ecuador, sede Manabí, Portoviejo, Ecuador

b Pontificia Universidad Católica del Ecuador, sede Manabí, Portoviejo, Ecuador

c Pontificia Universidad Católica del Ecuador, sede Manabí, Portoviejo, Ecuador

d Pontificia Universidad Católica del Ecuador, sede Manabí, Portoviejo, Ecuador 
3.3 Functions of the evaluation.

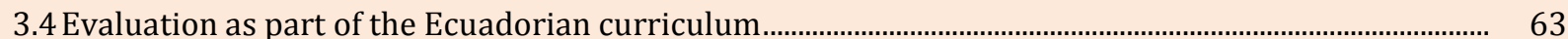

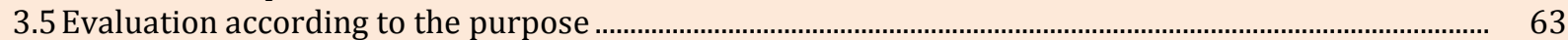

3.6 Authentic

3.7 Culture of the evaluation of the Ecuadorian teacher

3.8 Renewal evaluation practices.

4. Conclusion

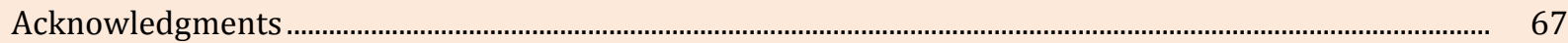

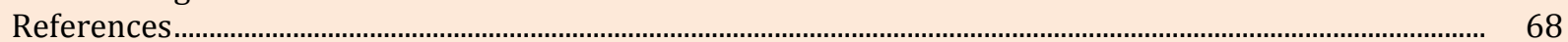

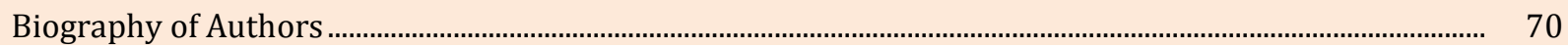

\section{Introduction}

The assessment of learning has been a subject of controversy for many years ago due to inappropriate approaches that the authorities and the teachers themselves opt in the educational institutions. According to the authors Navarro et al., (2017), the evaluation has been considered as a purely quantitative process in which the learning results are measured and valued, the achievement of the pre-established objectives is verified in order to improve quality educational

The teacher must conceive the evaluation as an integrative model, in which there is a horizontal, not vertical, approach between the learning characteristics of the students and the improvement in the educational practice, with this it is propitiated to obtain satisfactory results in the educational process, therefore the evaluation becomes an enriching and pleasant factor for the students, and in an instrument to obtain quality information that allows teachers to make the necessary modifications in the educational phenomenon.

It is essential that the teacher be able to interpret the evaluation with a formative, integral and qualitative sense more focused on the development of skills than on the contents of the teaching. The evaluation with a formative orientation aims to improve the educational quality because it rescues the active role of the actors in the teaching-learning process and promotes a collective dialogue (Chaverra, 2014).

The objective of this work was to investigate the evaluation approaches that teachers assume in the teaching-learning process in the Educational Unit "Edwin Hernán Mendoza Bravo", of the Colón parish, in order to know the evaluation practices of the teacher to achieve significant learning in students. The application of an adequate approach will allow the integral formation of the student so that, from the selfevaluation and analysis of his achievements, he knows how to develop and improve his abilities.

\section{Materials and Methods}

The proposed research was exploratory and was carried out in the Fiscal Education Unit "Edwin Hernán Mendoza Bravo" of the Santa Clara site of the Colón parish, Portoviejo canton, with the purpose of knowing the educational reality related to the approaches of the evaluation that teachers assume during the development of the teaching-learning process. For the writing of this document, a descriptive methodology and bibliographic research were used, the method of content analysis was used that allowed the objective and systematic description of the results of this research. The technique that allowed the collection of the data that support the elaboration of this article was through the survey directed to the teaching staff of the institution.

Tuarez, M. A. V., Delgado, M. A. C., Delgado, R. I. Z., \& Romero, J. E. V. (2019). Approaches to evaluation assumed by teachers on teaching process - learning. International Journal of Social Sciences and Humanities, 3(3), 60-70. https://doi.org/10.29332/ijssh.v3n3.361 


\section{Results and Discussions}

\subsection{Learning}

Evaluation The evaluation of learning is of vital importance in the educational process since this allows the teacher to have a clearer vision of the achievements and deficiencies that are in the students, and above all to verify if they are achieving the pre-established objectives.

The evaluation is as important as the learning itself because it occupies a relevant role in the reality of the classroom since it is assumed as an assessment and regulation of the teaching-learning process, which promotes the progress and scope of goals and objectives Preset

There are different ways to evaluate student learning, but if we intend to have a clear vision to determine the degree to which learning objectives are being achieved, it is necessary to distinguish the three types of evaluation that are given from the beginning to the end of any process educational. These evaluations are The diagnostic, formative and summative evaluation.

The diagnostic evaluation allows the teacher to verify the previous experiences that the student already has to give way to new knowledge, so it is carried out at the beginning of the course. The training is applied throughout the educational process in order to provide timely feedback that helps strengthen the knowledge acquired. The summative evaluation is present at the end of the course to verify if the objectives were achieved.

Of the three types of evaluation, formative evaluation allows learners to reflect where they are, where they can get there and how to do it in the educational process. Formative evaluation (Anijovich, 2017; Macías et al., 2018), is the opportunity that students have to strengthen their achievements, analyze and correct their mistakes in order to improve their learning.

The feedback in the formative evaluation is conceived as the opportunity of the teacher to obtain evidence about the learning of the students and to make the respective adjustments if necessary. In order for feedback to be effective, it must be carried out simultaneously (Canabal \& Margaleft, 2017; Hounhanou, 2018), the correction or suggestion must be exposed as soon as the problem has arisen in a task or activity, but without interrupting its progress.

\subsection{Evaluation approaches}

The evaluation of learning can be seen from two different perspectives or approaches: one that is based on a transformation proposal and the other that proposes a measurement pedagogy. The first focuses on understanding, learning, motivating, diagnosing, among others, to reach an educational improvement. The second one has the main objective to compare, classify, measure and obtain a grade or grade.

An evaluation can have a quantitative and qualitative approach, but the qualitative evaluation has great relevance because it does not measure how much; but the how, the progress and evolution of the student during the educational process, in addition that leads the teacher to issue a relevant judgment and leads to constant feedback in order to improve and transform the subject of education.

The qualitative evaluation is not reduced in checking the results or obtaining a grade through a test, but rather prepares the student in a meaningful and relevant way throughout the educational process. This type of evaluation leads to an enriching transformation stage that the student experiences during the same process (Moreno, 2016).

The evaluation that is launched must demand in the students, the desire to find solutions to the problems and conflicts that arise in the educational context where they develop, with the contribution of valid arguments that provide a quick and innovative solution for the institution, but mainly for themselves.

In order to achieve what is mentioned in the previous paragraph, it is necessary to apply educational strategies that intervene effectively in teaching and in the evaluation of competencies. The authors (Alonzo et al., 2015; Alava \& Martinez, 2019), argue that training in skills implies preparing students in the four knowledge (knowing, doing, being and living together) so that they can act correctly in the problems that arise.

The teaching and evaluation of competencies ensure the integral development of the student, providing in them skills, knowledge, critical and reflexive attitudes that make it a worthy reference to follow. The 
evaluation of competences implies the knowledge and action, reflection and active action of the student to acquire the necessary weapons and belong with dignity to a society that demands vertiginous changes.

\subsection{Functions of the evaluation}

In the educational field, the evaluation can be reflected in various factors that range from the acquisition of knowledge of the student and the daily work of the teacher to those issues that are manifested in the school environment and in society. The evaluation in the learning process fulfills a series of functions that occur both in learning and in the social needs of the education system (Drago, 2017).

In the evaluation of learning two functions are distinguished: the pedagogical and the social function. The authors (Diaz et al., 2017), argue that the pedagogical function is related to the regulation and improvement of educational quality and to the application of appropriate strategies so that students acquire significantly all imparted knowledge

The social function of the evaluation goes beyond the teaching and learning process, this is reflected in issues that the educational system and the community demand that they are fulfilled. To mention an example of this type of function, there is the certification of knowledge, which is conferred through an academic title to the subject as a symbol that has acquired knowledge and skills during an arduous learning process.

Pedagogical and social functions are closely related to the academic field but occur in periods other than the school environment. The first manifests itself at the beginning, during and after the educational process; while the second acquires relevance only at the end of this process, but both functions contribute with fundamental themes that provide meaning to the context of education.

\subsection{Evaluation as part of the Ecuadorian curriculum}

Evaluation as part of the Ecuadorian curriculum is an important and necessary aspect in any national education system from the formative point of view during the teaching-learning process as it provides the basis for decision making in terms of academic reinforcement or feedback that students must necessarily receive.

The evaluation should contribute to humanistic teaching that contributes to the integral formation of the student (Estévez, 2018), this should be oriented to the development of a critical and reflective thought that leads to improving the quality of life, academic, professional and labor of the student's Learners.

The evaluation of students is an aspect that facilitates the teaching and learning process and to understand the impact and outcome of educational programs. An essential measure for the success of the curriculum is the quality of student learning. It is essential to know the degree to which these have achieved the objectives set both for the improvement of teaching and for the evaluation of the same curriculum.

\subsection{Evaluation according to the purpose}

The evaluation is an important activity conceived as an inseparable element in the teaching-learning processes, it is present in each of the purposes to structure all the teaching activities according to it. This is characterized by being the points where you want to reach, the products to be obtained or the desired state of a situation, which becomes a reason or motivation to act (Vargas, 2011).

The evaluation process can also be understood as the reasons why teachers carry it out. In the evaluation of learning, three purposes are generally distinguished, such as diagnostic evaluation, formative evaluation, and summative evaluation. This section describes what each of these types of evaluation consists of, the purposes they pursue and some generalities regarding their application.

\section{a) Diagnostic}

Evaluation is a daily action, present in all human activities, so it has been defined and redefined according to the area to which it is applied. The diagnostic evaluation is the first to be applied without distention of areas. This allows demonstrating the level of knowledge that students have to be able to start from their result in the teaching process, applying appropriate strategies and methods for their learning (López 2010).

Tuarez, M. A. V., Delgado, M. A. C., Delgado, R. I. Z., \& Romero, J. E. V. (2019). Approaches to evaluation assumed by teachers on teaching process - learning. International Journal of Social Sciences and Humanities, 


\section{b) Formative}

Evaluation Formative evaluation has an important role throughout the teaching-student learning, this must be seen as a process, but it is not an end, nor can it be a punctual action, but an issue throughout the learning, which is planned by teachers. This evaluation not only identifies difficulties and errors but rather has to understand its causes and its link in the elements of the curriculum (Ahumada, 2014).

The formative evaluation will guide and improve the teaching-learning process by being continuous, which allows obtaining information on the academic progress of the students, facilitating the detection of the contents that require feedback (López 2010).

\section{c) Summative evaluation}

It is undoubtedly one of the best known that arises before the need to know how much they are learning and how students are evolving from the application of a set of varied techniques and instruments, it is executed at the end of a teaching-learning process with the purpose of knowing if the objectives that were set at the beginning were achieved, giving them a qualification of the knowledge and skills they have acquired (López 2010).

Occasionally, this type of evaluation is seen by most teachers as an important test, such as the best achievement or trophy that students can achieve, since some of the teachers see it as a sanctioning and determining instrument when it comes to promoting of year to his students. This is usually a mistake since all learners have different learning times and rhythms due to the different multiple intelligences that have been discovered.

\subsection{Authentic}

Evaluation is an essential process when learning, authentic evaluation offers us greater objectivity, new ways of evaluating, recognizing the error and learning from it, which starts from a constructivist conception of teaching and learning.

The authentic evaluation has to do with student participation and refers to the fact of evaluating authentic learning situations, that is, significant learning scenarios for the student; evaluates contextualized learning, relevant real-life issues (Ramírez, 2008).

Thus, authentic evaluation constitutes a training activity that allows regulating learning, that is, to understand, to provide feedback and to improve the processes involved in them, it is considered a different way of evaluating and innovating as an inseparable aspect of teaching and learning that contributes to creating an ideal environment that contributes to academic growth (Ahumada, 2005).

The advantages of the evaluation authenticate, is to offer interesting, active, joyful, emotional experiences among others, which leads to an excellent academic environment where the educated will develop skills and allow equitable opportunities to progress. But on certain occasions they become disadvantages, it is the case of a unique experience in the student, it is applicable when working with small groups, but impossible when working with a large group. The authentic evaluation allows the teacher to develop significant programs of new studies to know their successes and make the necessary corrections.

\subsection{Culture of the evaluation of the Ecuadorian teacher}

The teacher evaluation constitutes a formative proposal that promotes the constant improvement of the professionals immersed in the educational system of the country, making them capable of making correct decisions regarding the educational act. This should be framed in the contribution of information that directs reflection and transformation in a positive way.

In general, the evaluation of teachers will help to identify their weaknesses and strengths, which will allow the improvement of their actions in order to revalue their work and encourage meeting spaces with teachers and other professionals of the educational services, contributing from this way to improve education (Sarramona, 2004). 
Ecuador is in the way of implementing the evaluations, there is still much to improve, since adopting an evaluative culture has been an arduous process that at the beginning generated many conflicts. In the year 2008, the teachers in functions were summoned to submit in a mandatory way evidence that evidences their performance, which according to him (Mineduc, 2008), takes into account 4 dimensions: Learn to be, Learn to know, learn to teach and learn to live together. All these changes generated discomfort in Ecuadorian teachers, due to the low evaluative culture of the entire teaching staff in the country, which generated great educational disturbances.

In 2012, the National Institute of Educational Evaluation, Ineval, the body responsible for the evaluation of the National Education System with its own autonomy and which has currently implemented evaluations in the admission phase and in the ranking, emerges, these actions help to improve the quality of education (López, 2015).

\subsection{Renewal evaluation practices}

Incorporating changes in educational practices implies a comprehensive training approach that assesses the achievement of students according to their progress, taking into account their abilities through a qualitative and non-quantitative sanctioning vision (Serrano, 2002).

During the teaching-learning process, all training activities should be considered as part of the continuous evaluation, this is not an "in the eye" evaluation, it must be embodied in instruments that allow information to be collected, in order to perform the respective feedback.

In the classroom, there is a large number of student productions such as works, workshops, exhibitions, billboards, among others, are means of verifying student learning, as well as debates, representation, dramatizations, which are evaluated and they are part of the classroom documents, to evaluate them the teacher must use several techniques such as observation, written test, projects, debates, among others, using instruments such as the questionnaire, checklist, rubric, assessment scale, anecdotal record, which strengthen an innovative process leaving aside traditional practices (Mineduc, 2008).

In the development of the following section, the fieldwork carried out in the Educational Unit "Edwin Hernán Mendoza Bravo", in the city of Portoviejo, is presented. The results obtained through the survey applied to the 16 teachers of all educational levels of the campus, show the importance and reality of the evaluation approach in the teaching-learning process, in accordance with the current educational system.

Educational evaluation is an incessant task that must be understood as a procedure of orientation and feedback; it must be executed continuously throughout the teaching and learning process in order to analyze student performance and make pedagogical improvement decisions. Table 1 shows the responses of the teachers of the campus understudy, about the moments in which they apply the educational evaluation.

Table 1

Moments in which the educational evaluation is applied

\begin{tabular}{lll}
\hline Data & Frequency & $(\%)$ \\
\hline At the beginning of each unit & 1 & 6 \\
At the end of each unit & 4 & 25 \\
At the end of each partial & 5 & 31 \\
At the end of each quarter & 2 & 13 \\
During the whole teaching-learning process & 4 & 25 \\
\hline
\end{tabular}

Table 1 shows that $31 \%$ of teachers apply the student assessment at the end of each part; $25 \%$ during the entire teaching-learning process and at the end of each unit, another $13 \%$ of respondents apply it at the end of each quarter and at the end of each unit $6 \%$. These data show that some teachers do not correctly apply the evaluation process; The student evaluation is a continuous activity that allows students to analyze the achievements or competencies that students are acquiring with respect to a subject, taking into account the constructivist conception of the authentic evaluation, which consists in the objective assessment of the learning applied to situations and circumstances real, in environments where the student develops, promoting

Tuarez, M. A. V., Delgado, M. A. C., Delgado, R. I. Z., \& Romero, J. E. V. (2019). Approaches to evaluation assumed by teachers on teaching process - learning. International Journal of Social Sciences and Humanities,

3(3), 60-70. https://doi.org/10.29332/ijssh.v3n3.361 
their development. Table 2 shows the teacher's conception regarding the aspects that he considers important when obtaining the final grade of the student.

Table 2

Relevant aspects that the teacher considers when obtaining the final grade of the student

\begin{tabular}{lll}
\hline Data & Frequency & $(\%)$ \\
\hline Exam notes & 7 & 44 \\
Formative process & 7 & 44 \\
Behavior & 0 & 0 \\
Other & 2 & 13 \\
\hline
\end{tabular}

As seen in table 2, 44\% of teachers consider the training process (student performance and evolution throughout the educational process) and the mark of the exams as an aspect of relevance when obtaining the final average of the students, $13 \%$ take into account other aspects. Currently the Ecuadorian education system requires the weighting of a grade that represents the skills and abilities acquired by the student in a given time, this note is part of the analysis and average of a number of individual and group inputs that the student plays in the educational process, it is the teacher's job to evaluate the child taking into consideration the training process and not just the arbitrary placement of exam-based grades. The references of the study group demonstrate the prevalence of two approaches, one that focuses on the measurement of learning as a means to assess the knowledge acquired and another that considers the formative or transformative evaluation. Both are important at the time of obtaining a qualification, but the last one is more effective because it is formative, comprehensive, and qualitative and focuses on the development of skills. It is clear that the simple increase in the number of tests or exams will not reinforce learning, and logically it will not contribute to the human form of students.

One of the activities of the teaching management is to apply appropriate strategies and techniques to gather necessary information on the performance of students in the teaching-learning process, this must be done through assessment tools. Figure 1, shows the techniques that teachers usually apply to evaluate students.

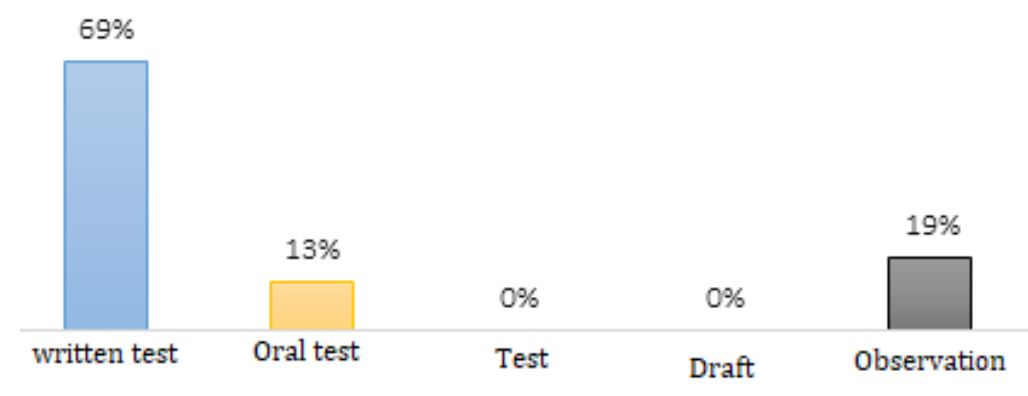

Figure 1. Evaluation techniques

It should be noted that there are currently several interactive and innovative ways of evaluating students with techniques of the great educational impact that help students develop their creativity, criticality, and reflection while learning. The essay, project, discourse, debate, experiments, infographics, inverted classroom, comic, among others, are trends in regards to education and their results are positive in the acquisition of significant learning. However, Figure 1 shows that one of the techniques most used by teachers is the written test reflecting $69 \%$, the oral test is used by $13 \%$ of respondents and $19 \%$ applies the observation technique. The results show that the essay and Project are not applied in this institution, the evaluation techniques are not very innovative and not at all creative, and the teachers limit themselves to adopting traditionalist strategies that generate little interest in the students. Figure 2 shows the most used assessment instruments in the teaching and learning process. 


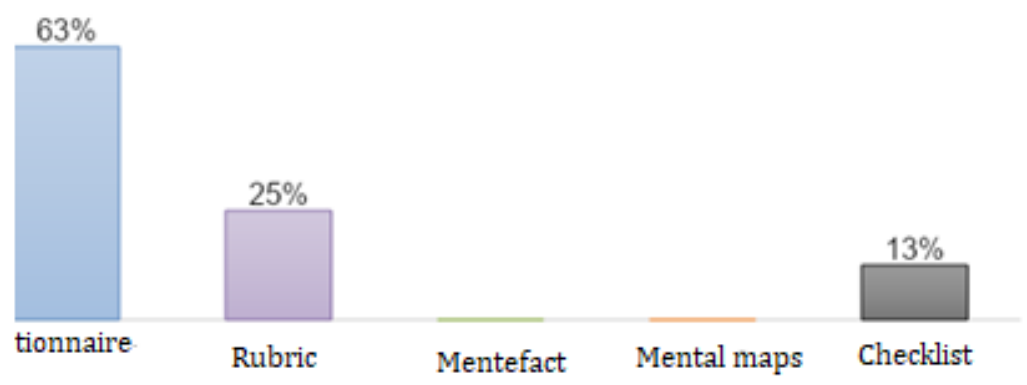

Figure 2. Evaluation instruments

In terms of applicability, the instrument preferred by teachers is the questionnaire with $63 \%$, followed by the rubric with $25 \%$, while $2 \%$ prefer the checklist. Due to the impact of evaluation on learning, it is essential to use and correctly apply different instruments that help measure student performance. Figure 2, affirms the answers obtained in graph 1 , the findings of this research allow us to interpret that there is a traditional approach to teaching and is reflected in the strategies, techniques, and instruments used; there are little preparation and predisposition of the teacher in the application of new teaching-learning strategies.

\section{Conclusion}

Most teachers do not apply educational evaluation during the entire teaching-learning process, the elements considered for the final averages focus on exam grades, a situation that evidences the latent presence of a quantitative approach to the qualitative or transformative.

Deficient authentic evaluation and non-innovative strategies are demonstrated, the prevalence of traditional teaching approaches affect the application of common techniques and instruments such as written test and questionnaire, these events limit the student to be unreflective and creative, they are not encouraged the creation of projects or practical activities that demonstrate the application of the knowledge acquired in the classroom.

\section{Acknowledgments}

The group of authors of this scientific article offers a sincere thanks to Dr. María Rodríguez Gámez, for the support provided throughout the process of preparing the document. For providing us with the relevant, useful and necessary guidelines and information for the timely realization of this work, in addition, that it intervened correctly in the edition and last revision of the article for its respective shipment.

Tuarez, M. A. V., Delgado, M. A. C., Delgado, R. I. Z., \& Romero, J. E. V. (2019). Approaches to evaluation assumed by teachers on teaching process - learning. International Journal of Social Sciences and Humanities, 3(3), 60-70. https://doi.org/10.29332/ijssh.v3n3.361 


\section{References}

Ahumada, P. (2005). La evaluación auténtica: un sistema para la obtención de evidencias y vivencias de los aprendizajes. Perspectiva Educacional, Formación de Profesores, (45), 11-24.

Ahumada, P. (2014). Teacher evaluation [Message in a blog]. http://profeeval.blogspot.com/2012/04/cargando.html

Alava, E. E., \& Martinez, M. E. M. (2019). Impact of teaching-learning process for brain. International Journal of Health Sciences, 3(1), 33-40. https://doi.org/10.29332/ijhs.v3n1.304

Alonzo, D., Valencia, M., Vargas, J. \& Bolívar, N. (2015). Strategies for the development of skills in the classroom, with a sociocognitive approach. Redipe Bulletin, 4 (9), 77-85. https://dialnet.unirioja.es/servlet/articulo?codigo $=6232397$

Anijovich, R. (2017). Formative evaluation in higher education. Voices of education, 2 (1), 31-38. https://dialnet.unirioja.es/descarga/articulo/6475459.pdf

Canabal, C \& Margalef, L. (2017). Feedback: The key to a learning oriented assessment. Journal of the $\begin{array}{llllll}\text { Curriculum and } & \text { Teacher } & \text { Training, } & \text { (1), } & \text { 150-170 }\end{array}$ https://recyt.fecyt.es/index.php/profesorado/article/view/59454

Chaverra, B. (2014). Meanings given to the evaluation of teaching and learning: Interpretation from a group of physical education teachers. Pedagogical studies (Valdivia), 40 (2), 65-82. http://dx.doi.org/10.4067/S0718-07052014000300004

Díaz, Y., Pérez, J., Moure, M., Pérez, A., Mayor F., and Mella, L. (2017). Essentials of the evaluation of learning in the teaching-educational process. Electronic Medical Journal, 39 (3), 620-629. http://scielo.sld.cu/scielo.php?script=sci_arttext\&pid=S1684-18242017000300022\&lng=en\&tlng=en.

Drago, C. (2017). Evaluation for learning. Teacher support manual. Central University. Santiago Chile. http://www.ucentral.cl/prontus_ucentral2012/site/artic/20170830/asocfile/20170830100642/manual_ evaluacion.pdf

Estévez, H. (2018). The evaluation of the learning in the integral formation of the students of basic education $\begin{array}{llllll}\text { and baccalaureate. } & \text { Challenges } & \text { of }\end{array}$ http://retosdelaciencia.com/Revistas/index.php/retos/article/download/216/117/

Hounhanou, A. V. (2018). Evaluating Benin EFL Learners Writing Composition during Final Exam. International Journal of Linguistics, Literature and Culture, 4(2), 9-23.

López, A. (2015). Proposal for an evaluation model for the Teacher of Basic and Baccalaureate Education as a strategy to strengthen the quality of education in Ecuador (undergraduate thesis). Pontifical Catholic University of Ecuador. http://repositorio.puce.edu.ec/handle/22000/10573

López, L. (2010). Diagnostic, formative and summative evaluation [Message in a blog]. http://evaluacionluisdaniel.blogspot.com/

Macías, EIP, Cedeño, HAC, \& Chávez, GMR (2018). Importance of Improving Resilience in Teaching-Learning Process of Students with Disabilities. International Research Journal of Management, IT and Social Sciences , 5 (2), 120-128.

Ministry of Education and Culture of Ecuador, (2008). Learning Evaluation. Quito https://www.evaluacion.gob.ec/wpcontent/uploads/downloads/2019/02/CIE_ResultadosEducativos18_20190109.pdf

Ministry of Education and Culture of Ecuador, (2008). Sistema Nacional de Evaluación y Rendición Social de Cuentas. Quito: Mineduc. https://educacion.gob.ec/sistemas-nacional-evaluacion/

Moreno, T. (2016). Evaluación del aprendizaje y para el aprendizaje. México: UAM, Unidad Cuajimalpa. http://www.casadelibrosabiertos.uam.mx/contenido/contenido/Libroelectronico/Evaluacion_del_aprend izaje_.pdf

Navarro, Narda G, Falconí A, A Vinicio, \& Espinoza Cordero, Jessica. (2017). El mejoramiento del proceso de evaluación de los estudiantes de la educación básica. Revista Universidad y Sociedad, 9(4), 58-69. http://scielo.sld.cu/scielo.php?script=sci_arttext\&pid=S2218-36202017000400008\&lng=es\&tlng=es.

Ramírez, M. (2008). Innovación de la práctica docente. Evaluación de los aprendizajes. https://innovatedocente.webnode.es/products/evaluacion-de-los-aprendizajes-ensayo-/

Sarramona, J. (2004). Factores e indicadores de calidad en educación. Barcelona. España: Octaedro. https://www.unav.edu/publicaciones/revistas/index.php/estudios-sobre-educacion/article/view/26157 
Serrano, S. (2002). La evaluación del aprendizaje: dimensiones y prácticas innovadoras. Educere, 6 (19), 247257. https://www.redalyc.org/pdf/356/35601902.pdf

Vargas, J. (2011). Reflexiones, citas e interrogantes sobre evaluación y calidad educativa. Lecturas de geografía e historia. https://josevargasponce.wordpress.com/2011/06/30/reflexiones-citas-e interrogantes-sobreevaluación-y-calidad-educativa/

Tuarez, M. A. V., Delgado, M. A. C., Delgado, R. I. Z., \& Romero, J. E. V. (2019). Approaches to evaluation assumed by teachers on teaching process - learning. International Journal of Social Sciences and Humanities, 3(3), 60-70. https://doi.org/10.29332/ijssh.v3n3.361 


\section{Biography of Authors}

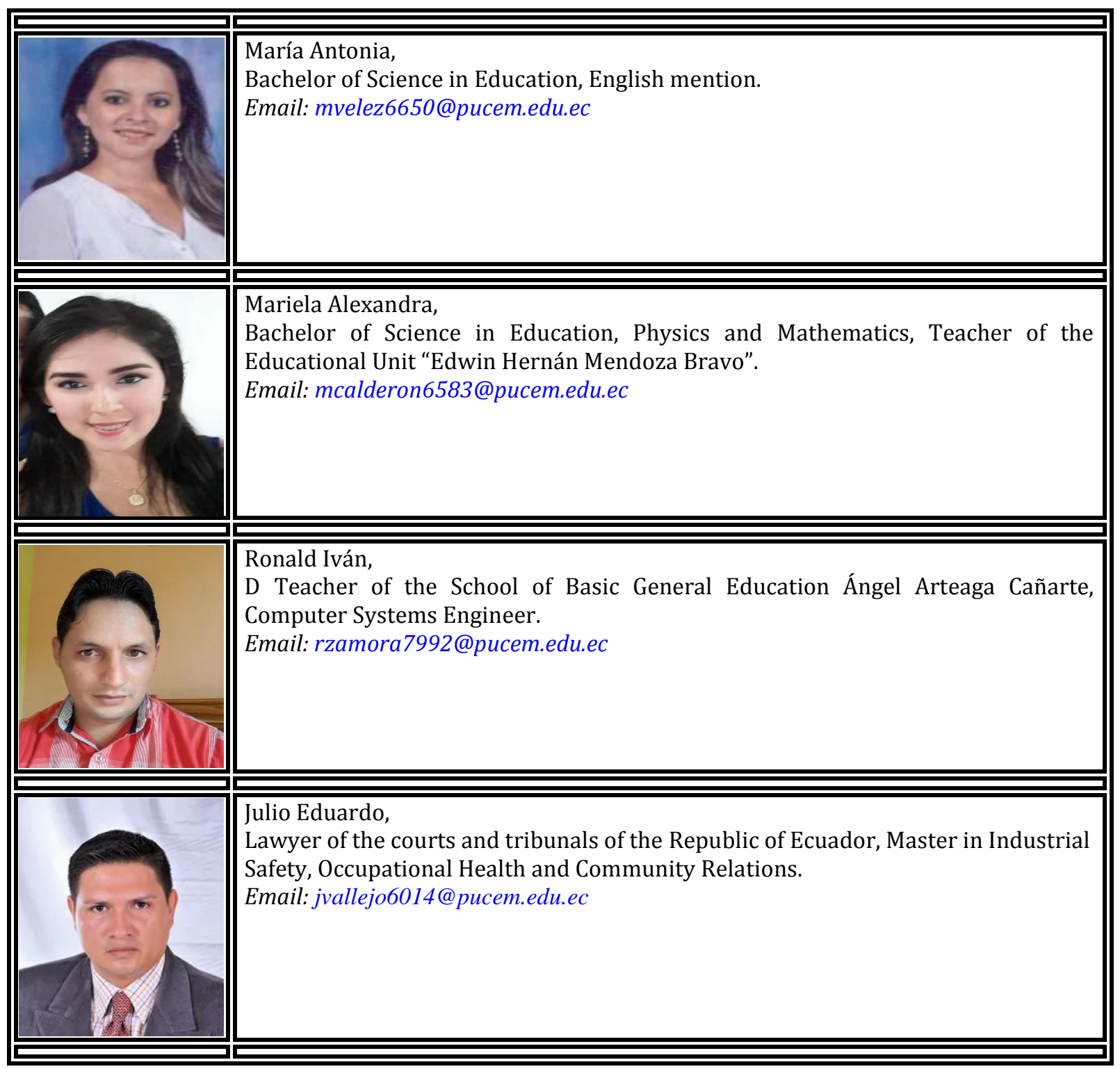

